\title{
Ethological evaluation of pig welfare under different keeping technologies in Siberian conditions
}

\author{
Konstantin Zhuchaev ${ }^{1, *}$, Dmitry Orlov $^{2}$, Ekaterina Borisenko ${ }^{1}$, Marina Kochneva ${ }^{1}$, and \\ Vladimir Hart ${ }^{1}$ \\ ${ }^{1}$ Federal State Budgetary Educational Institute of Higher Education "Novosibirsk State Agrarian \\ University", Laboratory of Animal Adaptation and Welfare, Novosibirsk, Russian Federation \\ ${ }^{2}$ Cargill, Russian Federation
}

\begin{abstract}
The authors found that the system of keeping gestating sows on a breeding farm increases the risk of animal welfare related to technological problems and insufficient staff training (contamination, human fear, local infections, inflammation of joints). The negative impact of industrial technology on the welfare of gestating sows is manifested in the increased frequency of torso injuries and fear of humans. Limb problems in sows on a farm kept without walking are related to a low management level, as no such problems were observed in the industrial complex. The welfare of sows on small farms can be ensured by improving the technological level of production and the skills of maintenance personnel.
\end{abstract}

\section{Introduction}

The quality of livestock products and animal health depends on a complex of factors that include the system of housing, feeding and veterinary prevention, features of indoor microclimate, the level of industry management [1] and heredity of animals [2].

Favourable conditions of housing contribute to the maintenance of the physiological status of the animal. Intensive technology with housing without walking increases the risk of disruption of the ordinary course of vital functions, which can cause various diseases in pigs [3]. In these conditions, the density of animal housing, diet structure, design features of the farm, including the air ventilation system, and climatic factors determine the welfare [4, 5].

The most significant microclimate problems are usually associated with industrial pig breeding technology (humidity, air velocity, concentration of harmful gases) [6, 7]. A monotonous environment harms the physical and mental condition of animals $[8,9]$. In extensive production systems, it is known that other threats to animal welfare may occur [10], mainly due to specific keeping conditions. In this regard, it is of particular interest to assess the welfare of pregnant sows under different technologies implemented under

\footnotetext{
* Corresponding author: zhuchaev-kv@mail.ru
} 
Siberian conditions. Ethological welfare evaluation is based on the study of behaviour and analysis of skin conditions in randomly selected animals.

\section{Materials and methods}

Studies were conducted on sows of 45-52 days of pregnancy in the summer period at 18 $22^{\circ} \mathrm{C}$ on three farms:

- Farm No. $1(\mathrm{n}=52)$ was an industrial pig farm. Keeping without walking, group size 20-25 animals, feeding with dry mixed fodder; PIC hybrids;

- Farm No. $2(\mathrm{n}=52)$ is a breeding farm with 100 direct sows. Small group housing (1012 animals in pen) with walking in the cage; feeding dry, balanced mixed fodder; an early maturing meat breed of pigs, local type;

- Farm No. $3(n=35)$ - a commercial pig farm for 100 head sows, without outdoor exercise, feeding with dry mixed feed prepared on the farm; Large White breed, local type.

The effect of walking on the welfare of gestating sows was evaluated by observations on breeding and commercial farms.

The effect of industrial housing technology on animal welfare was studied by comparative ethological evaluation of gestating sows at the industrial complex and at the commercial farm under keeping conditions without walking.

The authors evaluated the temperature, air velocity and relative humidity, the content of harmful gases (ammonia, hydrogen sulfide) and illumination in each row of stalls and the center of the building. The temperature was measured in two zones vertically at 0.6 and 1.5 $\mathrm{m}$ from the floor, the relative humidity - using a static psychrometer, the air velocity - using a katathermometer.

The welfare of sows was evaluated according to the method [11] on a three-point scale. In their study, the authors identified bursitis, lameness, infections of the body (one side), wounds on the body and vulva, hernias, local infections (abscesses and tumours). Fear of human was assessed by the presence of a unfamiliar man avoidance reaction.

Differences of variance between groups were assessed using the Kruskal-Wallace test. Further, differences between groups were determined using Dunn's criterion.

\section{Results and discussion}

During the period of observations, concentrations of ammonia and hydrogen sulfide in the animal houses of the industrial complex and a small commercial farm were approximately at the same level. They were within the MPC (20 and $10 \mathrm{mg} / \mathrm{m} 3$, respectively) (Table 1). The commercial farm was generally characterized by slightly worse indicators of harmful gases and air exchange in general. The temperature during the evaluation period ranged from 16 to $21^{\circ} \mathrm{C}$, slightly exceeding the upper limit of the comfort zone at the industrial complex and the commercial farm. At the same time, the relative humidity in these rooms did not exceed $50 \%$. Lighting, according to the standards, was provided only on the breeding farm [12].

Table 1. Parameters of the microclimate in pig houses.

\begin{tabular}{|c|c|c|c|}
\hline Indicator & Farm No.1 & Farm No. 2 & Farm No. 3 \\
\hline $\mathrm{NH}_{3}, \mathrm{mg} / \mathrm{m}^{\wedge} 3$ & $8.28 \pm 1.75$ & $4.98 \pm 1.6$ & $12.39 \pm 1.03$ \\
\hline $\mathrm{H}_{2} \mathrm{~S}, \mathrm{mg} / \mathrm{m}^{\wedge} 3$ & $0.18 \pm 0.07$ & $0.27 \pm 0.02$ & $0.63 \pm 0.05$ \\
\hline Average temperature, ${ }^{\circ} \mathrm{C}$ & $21.4 \pm 0.58$ & $16.3 \pm 0.16$ & $20.2 \pm 0.14$ \\
\hline Relative humidity, \% & $48.58 \pm 3.72$ & $73.46 \pm 3.2$ & $46.02 \pm 0.94$ \\
\hline
\end{tabular}




\begin{tabular}{|c|c|c|c|}
\hline Illumination, lux & $25.67 \pm 6.33$ & $30.76 \pm 16.16$ & $23.44 \pm 10.2$ \\
\hline Air speed, m/s & $0.17 \pm 0.1$ & $0.20 \pm 0.06$ & $0.02 \pm 0.02$ \\
\hline
\end{tabular}

In the absence of design differences between livestock buildings (brick enclosures, concrete floor and ceiling), the supply-exhaust ventilation of the breeding farm provided a better microclimate than that of the commercial farm.

Variance analysis of the data revealed an effect of the farm factor on torso contamination, local infection rates $(\mathrm{P}<0.001)$ and fear of human $(\mathrm{P}<0.01)$. The most contaminated were breeding farm pigs using the paddock.

The tendency to increase the frequency of lesions on the body and the vulva of sows in conditions of an industrial complex was revealed. Local infections (abscesses, inflammations) were much more frequent in breeding pigs.

The proportion of animals without bursitis was significantly higher on the commercial farm $(\mathrm{P}<0.01)$. At the same time, this farm was characterized by the worst condition of sows' limbs (Table 2).

Table 2. Assessment of the welfare of gestating sows under different keeping systems, $\%$.

\begin{tabular}{|c|c|c|c|c|}
\hline Indicator & Scores & Farm No. 1 & Farm No. 2 & Farm No. 3 \\
\hline \multirow[t]{3}{*}{ Presence of bursitis } & 0 & 98.1 & 75 & 96.6 \\
\hline & 1 & 1.9 & 20 & 3.4 \\
\hline & 2 & 0 & 5 & 0 \\
\hline \multirow[t]{3}{*}{ Contamination of the body } & 0 & 96.2 & 77.5 & 89.7 \\
\hline & 1 & 3.8 & 20 & 10.3 \\
\hline & 2 & 0 & 2.5 & 0 \\
\hline \multirow[t]{3}{*}{ Presence of a limp } & 0 & 96.2 & 92.5 & 79.3 \\
\hline & 1 & 3.8 & 5 & 13.8 \\
\hline & 2 & 0 & 2.5 & 6.9 \\
\hline \multirow{3}{*}{$\begin{array}{l}\text { Presence of wounds on the } \\
\text { body }\end{array}$} & 0 & 86.5 & 97.5 & 100 \\
\hline & 1 & 13.5 & 2.5 & 0 \\
\hline & 2 & 0 & 0 & 0 \\
\hline \multirow[t]{3}{*}{ Presence of hernias } & 0 & 100 & 100 & 100 \\
\hline & 1 & 0 & 0 & 0 \\
\hline & 2 & 0 & 0 & 0 \\
\hline \multirow{3}{*}{$\begin{array}{l}\text { Existence of damage to the } \\
\text { vulva }\end{array}$} & 0 & 92.3 & 97.5 & 96.6 \\
\hline & 1 & 7.7 & 0 & 3.4 \\
\hline & 2 & 0 & 2.5 & 0 \\
\hline \multirow{3}{*}{$\begin{array}{l}\text { Presence of localized } \\
\text { infections }\end{array}$} & 0 & 96.2 & 55 & 100 \\
\hline & 1 & 1.9 & 32.5 & 0 \\
\hline & 2 & 1.9 & 12.5 & 0 \\
\hline \multirow[t]{3}{*}{ Fear of human } & 0 & 17.3 & 25 & 58.6 \\
\hline & 1 & 13.5 & 32.5 & 17.2 \\
\hline & 2 & 69.2 & 42.5 & 24.2 \\
\hline
\end{tabular}

In terms of the percentage of sows that exhibited a high fear of human, the industrial complex outperformed other farms. However, the breeding farm also had a high rate of fearful animals (up to $75 \%$ ), probably due to the insufficient qualification of the working staff. 
Animal reactions to the influence of environmental factors are interrelated [13]. Animal behaviour serves as an external manifestation of adaptation processes [14]. In turn, restrictions in the expression of natural behaviour violate the welfare of pigs, causing discomfort and anxiety [15].

The crowding in the placement of animals and the reduction of individual distance contribute to a change in the hierarchy in the herd, an increase in aggressiveness and cannibalism [6]. It has been shown that the housing technology with walking increases the duration of exploratory and motor activity of pigs and significantly reduces the incidence of cannibalism compared to housing without walking [16].

Wounds on the body and vulva of sows are the consequence of aggressive interactions $[17,18]$. In addition, aggressive interactions increase the degree of animal contamination and the risk of diseases. The authors found in their studies a tendency to an increased frequency of injuries on the body and the vulva of sows in the conditions of an industrial complex with a slightly lower degree of contamination than on other farms.

The most contaminated were the pigs of the breeding farm, which have the possibility of walking. At the same time, local infections (abscesses, inflammations) were much more frequent in them.

The reliable effect of the walking system on farm No.2 on the frequency of local infections and the human reaction was shown $(\mathrm{P}<0,01)$. Bursitis, abscesses and tumours were significantly more common on the breeding farm than smallholder farmers with no paddock housing.

Animals with high fear of human change behaviour, there is constant stress, which causes a decrease in productivity and product quality [19, 20, 21].

In the industrial complex, the proportion of animals with high fear of human significantly exceeded the proportion of animals in the commercial farm $(\mathrm{P}<0.001)$, which can be explained by the inability of pigs to exhibit natural behaviour [15] and rare contacts with personnel, as well as the rough treatment of animals $[19,20]$. In conditions with walking animals on the breeding farm, the increased fearfulness of the pigs is related to the improper work of the maintenance personnel when moving them to the walking areas.

The proportion of animals without bunions was significantly higher on the commercial farm $(\mathrm{P}<0.01)$, but this farm was characterized by worse limb conditions. Since the type of flooring on the compared farms is the same, the reason could be systemic management problems leading to an increase in the culling of animals due to impaired reproductive functions and productivity.

The identified ethological features of pigs under different housing technologies indicate that the enrichment of the walking environment, which has a favourable effect on the psychological state of sows, at the same time increases the risk of animal disadvantage associated with human fear, local infections, inflammation of the joints. The advantages of the paddock system are thus offset by technological problems related to staff qualifications.

\section{Conclusions}

Thus, the system of keeping gestating sows in conditions of the breeding farm with insufficient personnel training and technological problems is associated with an increased risk of animal welfare (contamination, fear of human, local infections, inflammation of joints).

The negative impact of industrial technology on the welfare of gestating sows is manifested in the increased frequency of torso injuries and increased fear of human. Limb problems in sows on a farm kept without paddock are related to a low management level, as no such problems were observed in the industrial complex. 
The welfare of sows on small farms can be ensured by improving the technological level of production and the skills of service personnel.

\section{References}

1. S. Stoier, H.D. Larsen, M.D. Aaslyng, L. Lykke. Meat Sci. 120 (2016) https://doi.org/10.1016/j.meatsci.2016.04.010

2. L. Faucitano, Can J. Anim Sci. 90(4) (2010) https://doi.org/10.4141/cjas 10020

3. S. Pietrosemoli, C. Tang, Agriculture 10(6) (2020) https://doi.org/10.3390/agriculture 10060223

4. J. Švajlenka, M. Kozlovská, T. Pošiváková, Environ Monit Assess 191 (2019) https://doi.org/10.1007/s10661-019-7608-8

5. D.A. Orlov, T.Jungbluth, K.V. Zhuchaev, M.L. Kochneva, O.V. Bogdanova, N. Hammer, J. Threm. Biosci. Biotechnol. Res. Asia 13, 2 (2016) https://doi.org/10.13005/bbra/2091

6. V.E. Beattie, N. Walker, I.A. Sneddon, Appl. Anim. Behav. Sci. 48(3-4) (1996)

7. Y. Cao, Z. Bai, T. Misselbrook, X. Wang, L. Ma. J Air Waste Manage 71(1) (2021) https://doi.org/10.1080/10962247.2020.1815895

8. R.F. Oliveira, R.T.R.N. Soares, J.P. Molino, R.L. Costa, T.P. Bonaparte, E.T. Silva, I.P. Santos, Arq Bras Med Vet Zoo 68 (2016) https://doi.org/10.1590/1678-4162-8253

9. K. Scott, L. Taylor, B.P. Gill, S.A. Edwards, Appl. Anim. Behav. Sci. 105 (2007) https://doi.org/10.1016/j.applanim.2006.05.042

10. D. Temple, V. Courboulay, X. Manteca, A. Velarde, A. Dalmau, Animals 6(4) (2012) https://doi.org/10.1017/S1751731111001868

11. Welfare Quality ${ }^{\circledR}$ Assessment Protocol for Pigs (Sow and Piglets, Growing and Finishing Pigs); Welfare Quality ${ }^{\circledR}$ Consortium, (Lelystad, The Netherlands, 2009)

12. L.B. Prikupets, Light Eng. 26(1) (2018)

13. W. Halfwerk, H. Slabbekoorn, Biol Lett. 11 (2015) https://doi.org/10.1098/rsb 1.2014.1051

14. L. Canario, S. Mignon-Grasteau, M. Dupont-Nivet, F. Phocas, Animals 7(3) (2013) https://doi.org/10.1017/S1751731112001978

15. H.W. Gonyou, Appl. Anim. Behav. Sci. 72(21) (1994)

16. J.H. Guy, P. Rowlinson, J.P. Chadwick, M. Ellis, Appl. Anim. Behav. Sci. 75(3) (2002) https://doi.org/10.1016/S0168-1591(01)00197-6

17. P. Jensen, Appl. Anim. Ethol. 6(4) (1980) https://doi.org/10.1016/0304-3762(80)9 0134-0

18. EFSA Panel on Animal Health and Welfare (AHAW). J. EFSA 10(1) (2012) https://doi.org/10.2903/j.efsa.2012.2512

19. T. Grandin, Agri-Practice 9(4) (1988)

20. P.H. Hemsworth, J.L. Barnett, C. Hansen. Appl. Anim. Behav. Sci. 17(3-4) (1987) https://doi.org/10.1016/0168-1591(87)90149-3

21. P. Statham, L. Green, M. Mendl, Appl. Anim. Behav. Sci. 134(3-4) (2011) https://doi.org/10.1016/j.applanim.2011.08.009 